\section{Some serial properties of burst responding on DRL}

\author{
RONALD J. BRADLEY \\ New Parameters, Inc., 6101 Marble N.E., Albuquerque, N. Mex. 87108
}

A sequential IRT analysis was carried out on the response output of two rats on DRL $15 \mathrm{sec}$ LH $5 \mathrm{sec}$. It was found that burst responding (1) did not occur after a reinforced response, (2) was more likely to follow a nonreinforced response if the latter was preceded by a reinforced response, $(3)$ increased in probability after a nonreinforced response when the prior run of reinforced responses was greater than one, and (4) decreased in probability as the last successfully timed response became more remote. As reinforcement on this schedule is known to initiate a more precise temporal discrimination, it was hypothesized that these results might explain a previously reported finding that burst responding increases in probability as an IRT approaches the lower bound of the reinforcement interval.

Behavioral schedules incorporating the differential reinforcement of a low rate (DRL) usually give a bimodal interresponse time (IRT) distribution. After training, Ss may produce a response peak around the lower bound of the reinforcement interval and another peak at very short IRT values, often referred to as burst responding or bursting.

Knowledge of the underlying control of burst responding on DRL schedules has not progressed far since the first observations of Sidman $(1955,1956)$.

Bursting has been described by Anger (1955), Conrad et al (1958), Brady \& Conrad (1960), and Ayers \& Thompson (1961). Kelleher, Fry, \& Cook (1959), using a food-pellet reinforcer, found very few short IRTs on DRL. They hypothesized that these IRTs could be a function of adventitious reinforcement induced during the finite operating time of a dipper mechanism. However, Laties \& Weiss (1962) have shown that liquid reinforcement does not guarantee the occurrence of very short IRTs, and Bradley (1966) found significant amounts of bursting on food-reinforced DRL. Corman \& Shafer (1966) proposed that such IRTs might be reinforced if they were produced during the time taken to ingest a reinforcement. They tested this theory by spatial separation of the lever and reinforcement mechanism. Burst responding stabilized at around $20 \%$ of the total response output, so it would appear that consummatory behavior is not involved in acquisition. In the DRL schedule, burst responding is never overtly reinforced; therefore, it should eventually extinguish. In fact, Bradley (1967) found that during DRL training in the rat, bursting decreased from around $30 \%$ to as low as $2 \%$ after 160 consecutive training sessions.

Sidman (1956) also demonstrated that the probability of a burst response tended to increase as IRTs approached the lower bound of the reinforcement criterion, and he pointed out that this relationship might be indicative of dependencies even more removed in time.

In the present experiment, the IRTs obtained from a DRL baseline were processed by computer so that further serial dependencies might be investigated.

\section{SUBJECTS}

The Ss were two experimentally naive brown hooded rats, F8 and F9, approximately 90 days old at the beginning of the experiment. A 22-h water-deprivation regimen was maintained throughout, and food was available ad lib in the home cage.

\section{APPARATUS}

The experimental chamber, enclosed in a soundproofed and ventilated chest, was fitted with a solenoid-operated dipper mechanism located directly beneath a single lever. All programming and recording equipment was contained in a separate room. The behavior was monitored, using closed-circuit television, and the IRTs were recorded in sequence and punched on paper tape for subsequent computer analysis.

\section{PROCEDURE}

After receiving 50 reinforcements on a continuous reinforcement schedule for 2 consecutive days, the Ss were exposed to DRL $15 \mathrm{sec}$ for seven daily 2 -h sessions. The schedule was then altered by the addition of a limited-hold ( $\mathrm{LH}$ ) contingency, resulting in DRL $15 \mathrm{sec}$ LH $5 \mathrm{sec}$, i.e., only IRTs between 15 and $20 \mathrm{sec}$ were reinforced. From this point on, an experimental session was reduced to $90 \mathrm{~min}$ duration. Reinforcement consisted of $0.1 \mathrm{ml}$ of water presented for $1.5 \mathrm{sec}$, and the DRL interval was timed from the onset of reinforcement. Training was continued for 110 consecutive daily sessions.
After each session, the animals were given access to a water bottle for $15 \mathrm{~min}$. Data processing was carried out on the total IRT output of the next nine sessions for both animals. Due to a hardware problem, data for the third daily session was lost for Animal F8.

\section{RESULTS AND DISCUSSION}

A total of 2,958 IRTs were recorded from F9 and 2,572 IRTs from F8. Of the total response output, F9 produced $14 \%$ of IRTs less than 2 sec in duration and F8 produced $11 \%$. For the purpose of computation, a burst response or IRT complex (B) was defined according to Sidman (1956), as follows: "Any sequence of two or more responses in which no consecutive responses are separated by more than two seconds." $S^{R}$ was a reinforced response where $15 \mathrm{sec} \leqslant$ IRT $<20$ sec. $N$ refers to any nonreinforced IRT excluding IRTs less than 2 sec. There are therefore three types of response in our basic classification: reinforced responses, nonreinforced responses, and bursts. For the notation used in this paper, $\operatorname{Pr}\left(B \mid S^{R} N\right)$ would be the conditional probability of a burst response (B), given the occurrence of a nonreinforced response $(N)$ preceded by a reinforcement ( $S^{R}$ ). Where numbers are used to describe IRT bands, $\mathrm{X}$ would refer to an IRT falling within the limits, $\mathrm{X}$ sec $\leqslant$ IRT $<$ $(X+1)$ sec.

Using these definitions (Fig. 1), the calculation of second-order conditional probabilities supported the original findings of Sidman (1956). As an unreinforced IRT approached the lower bound of the $S^{R}$ interval, i.e.,
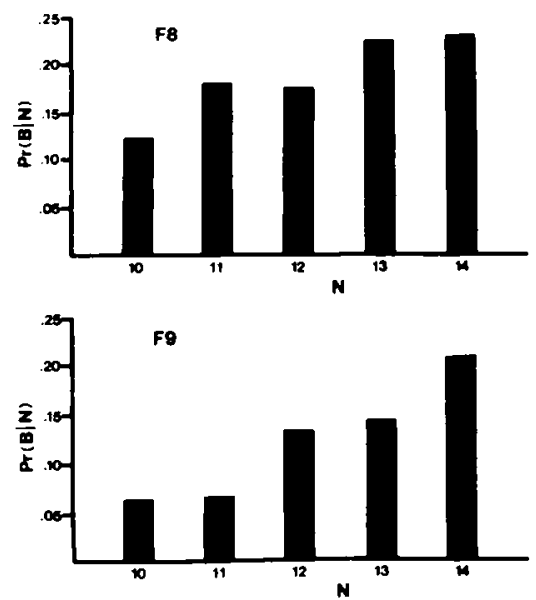

Fig. 1. Second-order conditional probability of burst responding (B) following a nonreinforced response (N). Probabilities are given for five 1 -sec IRT bands, where Band $X$ signifies $X$ sec $\leqslant$ IRT $<(X+1)$ sec, i.e., 12 refers to an IRT where 12 sec $\leqslant$ IRT $<13$ sec. 

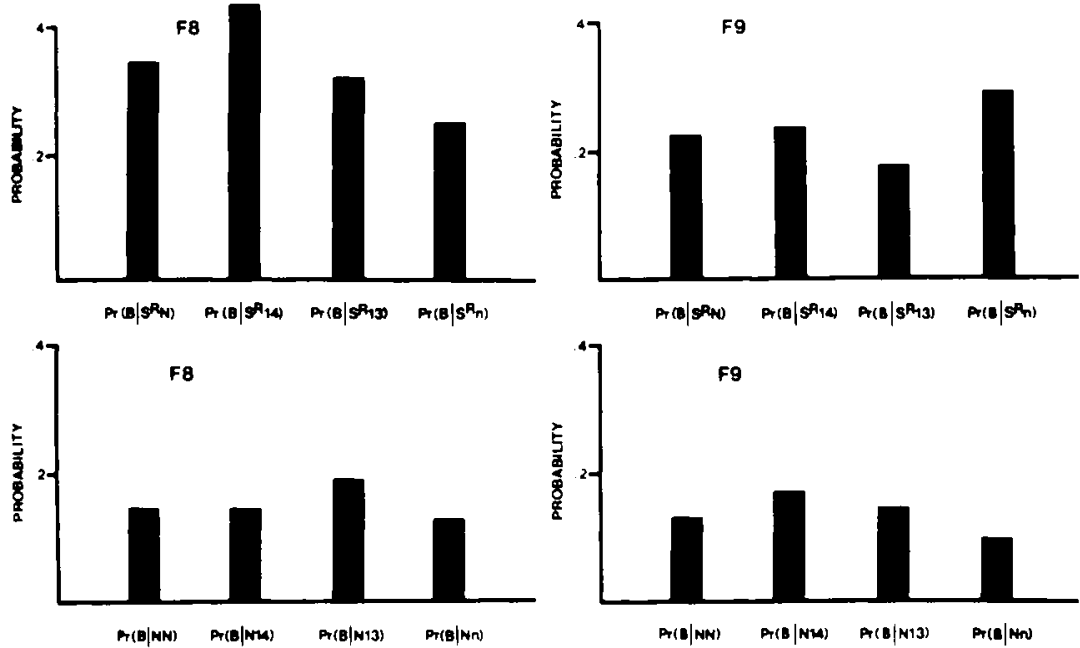

Fig. 2. Third-order conditional probabilities of bursting $B$ following response pairs of reinforced ( $S^{R}$ ) and nonreinforced (N) IRTs. Top : B preceded by the pair, $S^{R} N$, i.e., $\operatorname{Pr}\left(B \mid S^{R} N\right)$. Bottom: B preceded by the pair $N N$, i.e., $\operatorname{Pr}(B \mid N N)$. $N$ is further subdivided into the 13- and 14-sec IRT bands and Category "n," which includes any member of Class $N$ not falling within Bands 13 and 14 .

$15 \mathrm{sec}$, then the probability of bursting increased. However, when higher order conditional probabilities were calculated, it was found that the relationship between burst responding and the preceding IRT was further dependent upon whether the first response of a triad was reinforced. In Fig. 2 it can be seen that the value of $\operatorname{Pr}\left(B S^{R} N\right)$ is twice as great as $\operatorname{Pr}(B: N N)$. This result was also calculated for the 13- and 14-sec bins and summed for the remaining values of $N$, i.e., "n" where $2<n<13$. The predominance of the triad $\mathrm{S}^{\mathrm{R}} \mathrm{NB}$ in these records is overwhelming and readily catches the eye when scrutinizing the cumulative records. In order words, a nonreinforced response was more likely to be followed by very short IRTs if it was preceded by a reinforced response. On no occasion in this experiment did a short IRT appear immediately after a reinforced response.

Another type of analysis was invoked in order to determine if burst responding was affected by even longer serial dependencies (Fig. 3 ). It was discovered that as a run of nonreinforced responses increased in length, the probability of bursting
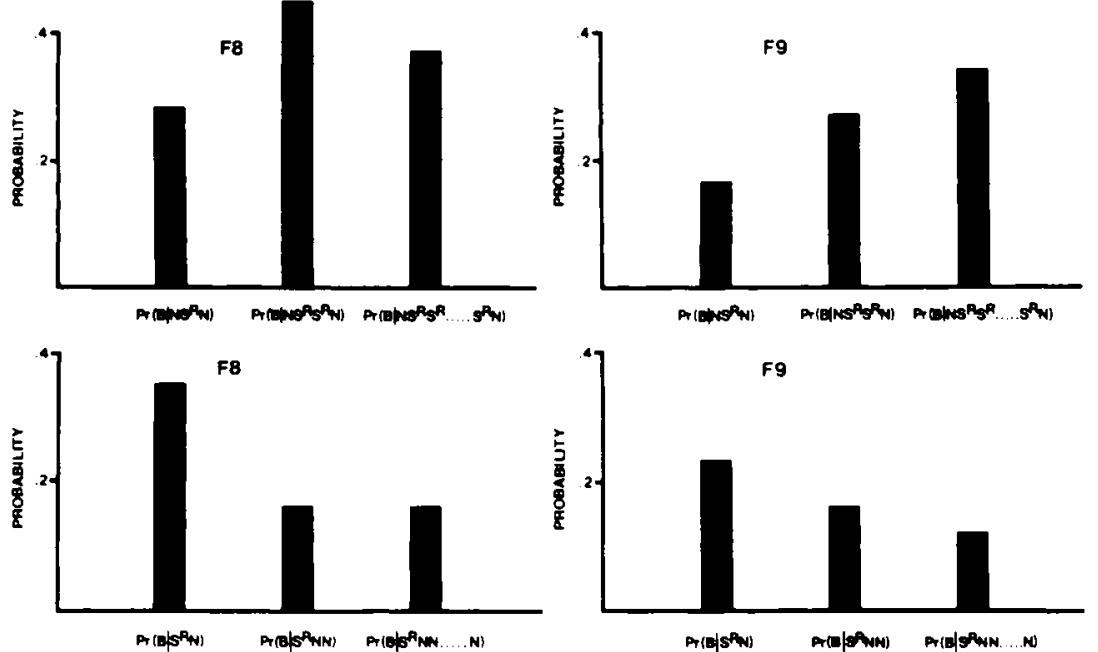

Fig. 3. Higher level conditional probability of bursting (B) following sequences of reinforced $\left(S^{R}\right)$ and nonreinforced $(N)$ responses. $S^{R} S^{R} \ldots \ldots S^{R}$ and $\mathrm{NN} \ldots . \mathrm{N}$ refer to all unbroken runs of three or more reinforced or nonreinforced responses. Top: $S^{R}$ runs of 1,2 , or $\geqslant 3$ responses. Bottom: $N$ runs of 1,2 , or $>3$ responses. decreased. Furthermore, the probability of bursting following a nonreinforced response was greater if that nonreinforced response was preceded by a run of more than one reinforcement.

These results may offer an explanation of the phenomenon discussed by Sidman of increased burst probability as the preceding IRT increases in length. It has been shown that there is a more precise IRT distribution after a reinforcement than after a nonreinforced response (Farmer \& Schoenfeld, 1964; Bradley, 1967). That is, unreinforced IRTs nearer to the lower bound of the reinforcement interval are more probable after a reinforcement than after a nonreinforced response. Also, we have seen that bursting is more likely to follow the sequence $\mathrm{S}^{R} \mathrm{~N}$. Therefore, there is manifested an increase in $\operatorname{Pr}(B \mid N)$ where $N$ approaches $15 \mathrm{sec}$. This second-order dependency might then be explained by considering it as an artifact produced by at least third-order contingencies.

\section{REFERENCES}

ANGER. D. The dependence of interresponse times upon the relative reinforcement of different interresponse times. Unpublished doctoral dissertation. Harrard University, 1955.

AYERS, W. J., \& THOMPSON, R. L. Properties of interresponse time distributions obtained during differential reinforcement of temporally spaced responses. American Psychologist, 1961. 16,458

BRADLEY, R. J. Timing behaviour in the rat Paper read at the Experimental Psychology Society meeting, Cambridge, England, 1966

BRADLEY, R. J. Some properties of behavioral baselines and disruption by the hallucinogenic drugs. Unpublished doctoral dissertation, University of Edinburgh, 1967.

BRADY, J. V.. \& CONRAD, D. G. Some effects of brain stimulation on timing behavior. Journal of the Experimental Analysis of Behavior, 1960, 3, 93-106.

CONRAD, D. G., SIDMAN, M., \& HERNSTEIN, R. J. The effect of deprivation upon temporally spaced responding. Journal of the Experimental Analysis of Behavior, 1958, 1, 59-65.

CORMAN. C. H.. \& SHAFER, J. N. The effect of spatial separation of response and reinforcement on DRL performance. Psychonomic Science, 1966, 6, 21-22.

FARMER, J., \& SCHOENFELD, W. N. Inter-reinforcement times for the barpressing response of white rats on two DRL schedules. Journal of the Experimental Analysis of Behavior, 1964, 7, 119-122.

KELLEHER, R. T., FRY, W. \& COOK, L. Interresponse time distributions as a function of differential reinforcement of temporally spaced responses. Journal of the Experimental Analysis of Behavior. $1959,2,91-106$.

LATIES. V. G.. \& WEISS, B. Effects of alcohol on timing behavior. Journal of Comparative \& Physiological Psvchology. 1962, 55, 85-91.

SIDMAN. M. Some properties of the 
warning stimulus in avoidance behavior. Journal of Comparative \& Physiological Psychology, 1955, 48, 444-450.

SIDMAN, M. Time discrimination and behavior interaction in a free operant situation. Journal of Comparative \& Physiological Psychology, 1956, 49. 469-473.

\section{Effects of the frequency of amplitude- modulated signals on the auditory evoked response}

\author{
MARTIN L. LENHARDT \\ Department of Surgery, Johns Hopkins University, Baltimore, Md. 21205
}

The relationship of the $N_{1} P_{2}$ voltage of the auditory averaged evoked response elicited by amplitude modulation has been studied. The stimuli were monaurally presented steady tones of $0.5,2.0$, and $4.0 \mathrm{kHz}$ at $60-\mathrm{dB} \mathrm{HL}$, with $10-\mathrm{dB}$ ramp modulations every $5 \mathrm{sec}$. The amplitude of the response decreased as the frequency increased.

The effects of the frequency of transient signals on the averaged auditory evoked response (AER) amplitude have been observed by Antinoro \& Skinner (1968), Evans \& Deatherage (1969), and Rothman (1970).

Generally, the data indicate a negative relationship between frequency and AER amplitude, e.g., the amplitude decreases progressively as the frequency increases. The observers are of the opinion that the AER amplitude is related to the number of neural units activated in the cochlea. Lower frequencies produce a much greater disturbance of the basilar membrane than do higher frequencies.

This hypothesis would predict that an increase in intensity of a continuous tone, which is physiologically reflected in an increased number of fibers activated, would result in a proportionally similar frequency effect. The study reported here was designed to investigate the effect of the frequency of amplitude-modulated (AM) tones on the amplitude of the averaged auditory evoked response.

\section{METHOD}

The Ss were four young adults with hearing within normal limits for the stimuli used in the study. Tones were generated by a custom-built audiometer. The continuous signals were pure tones of $0.5,2.0$, and $4.0 \mathrm{kHz}$, at an intensity of $60-\mathrm{dB} \mathrm{HL}$. At 5-sec intervals, the intensity was i n c rea sed 10 d B . The amplitude-modulated signals had a rise time of $25 \mathrm{msec}$ and a duration of $300 \mathrm{msec}$. The tones were prèsented monaurally through headphones while Ss were seated in a sound-attenuated chamber.

Electroencephalic activity was recorded from solder electrodes at vertex, referred to left mastoid with a forehead ground. Responses were summated over 70 presentations by a Nuclear Datal Enhancetron 1024 and written out by an $X-Y$ plotter. The analysis time was $4 \mathrm{sec}$. The amplitude of the first negative and second

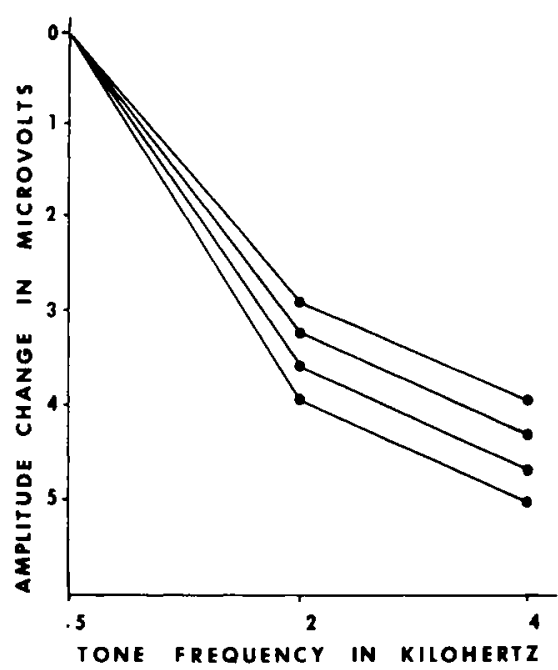

Fig. 1. Amplitude change (re $0.5-\mathrm{kHz}$ response) as a function of the frequency of amplitude modulated tones is plotted for four Ss. positive waveform peaks was measured. The decrease in voltage at 2.0 and $4.0 \mathrm{kHz}$ was assessed relative to the $0.5-\mathrm{kHz}$ amplitude.

\section{RESULTS}

The results are summarized in Fig. 1. The relative decrease in voltage is plotted as a function of frequency. The amplitude difference values averaged over the four $S$ s resulted in a mean decrease of $3.4 \mathrm{microV}$ for $2.0 \mathrm{kHz}$ and a mean decrease of $4.5 \mathrm{micro} V$ for $4.0 \mathrm{kHz}$ re: $0.5-\mathrm{kHz}$ amplitude.

\section{DISCUSSION}

A general finding that amplitude decreases as frequency increases has led to the assumption that the increased neural units stimulated by the lower frequency are responsible for the differences in the audioelectroencephalogram. A similar frequency effect was noted by $\mathrm{L}$ e n h a r t $\left(\begin{array}{lll}1971\end{array}\right)$ f or frequency-modulated tones. A tone that swept from 0.5 to $0.55 \mathrm{kHz}$ elicited a mean increase of 3.4 microV over a tone that swept from 2.0 to $2.2 \mathrm{kHz}$. The identical $N_{1} P_{2}$ voltage found in this study, using another method of stimulation (AM) within a frequency region, adds credibility to the assertion that the frequency effect is, indeed, real.

In summary, the explanation relating the increased amplitude to increased neural activity at the cochlea is applicable to transient signals of different frequencies, steady tones with frequency modulation, and steady tones with amplitude modulation. At this time, the evidence is not conclusive but suggestive. The averaging technique is still not appropriate for measuring the effect of frequency without confounding it with other parameter changes. In judging the importance of the findings, stimuli frequency, if not critical, should be low to elicit the greatest evoked signal in the background noise. Clinically, a response elicited with a low-frequency stimulus but not with a high-frequency stimulus at the same intensity may not be exclusively a result of a loss of acuity but due to the nature of the AER.

\section{REFERENCES}

ANTINORO, F., \& SKINNER, P. H. The effects of frequency on the auditory evoked response. Journal of Auditory Research, 1968, 8, 119-123.

EVANS, T. R., \& DEATHERAGE, B. H. The effect of frequency on the auditory evoked response. Psychonomic Science, $1969,15,95-96$

LENHARDT, M. L. Effects of frequency modulation on the auditory averaged evoked response. Audiology, 1971, 10 , 18-22.

ROTHMAN, H. H. Effects of high frequencies and intersubject variability on the auditory-evoked cortical response. Journal of the Acoustical Society of America, 1970, 47, 569-573. 